\title{
Conflict of Interest: Can We Minimize Its Influence in the Biomedical Literature?
}

Two articles in the Ethics Feature of the current issue highlight the growing concerns with the validity of the biomedical literature and recommended guidelines for clinical practice. Genuis ${ }^{1}$ and Abramson and Starfield ${ }^{2}$ discuss the influence of commercial funding on clinical practice guidelines. Genuis emphasizes the need to be wary of "standards of care" and for physicians to exercise independence in clinical practice. Abramson and Starfield present case studies that illustrate how pharmaceutical-sponsored research may affect biomedical publications, marketing, and ultimately medical practice. (Note: Although 7 ABFP prefers to use the generic name of drugs, an exception to that policy has been made in the Abramson and Starfield article, because of its focus on the marketing of 2 name brands, rather than on the use or effectiveness of these medications.)

These articles echo many of the concerns that are being voiced about the integrity of biomedical research and its literature and present an opportunity to review conflict of interest ethical standards and $7 A B F P$ policies that are intended to maintain the integrity of our journal.

What is a conflicting or competing interest, and how does it affect science and medical practice? Thompson ${ }^{3}$ defined conflict of interest as "a set of conditions in which professional judgment concerning a primary interest tends to be unduly influenced by a secondary interest." Primary interests are determined by the professional duties of a physician, scholar, or teacher (ie, the health and welfare of patients, validity of research, and mentoring and education of students). In the context of a medical journal, primary objectives are to select unbiased

Submitted, revised 19 July 2005.

From the Department of Family Medicine, Wayne State University, Detroit, MI (AVN, KLS); and Department of Family Practice and Community Medicine, University of Pennsylvania, Philadelphia, PA (MAB).

Conflict of interest: none declared.

Corresponding author: Anne Victoria Neale, PhD, MPH, Department of Family Medicine, 101 E. Alexandrine, Detroit, MI 48201 (e-mail: vneale@med.wayne.edu). questions for study, to describe research accurately, and to discuss interpretations and limitations fairly. ${ }^{4}$ A secondary interest is a motivation (such as financial gain, a personal relationship, or intellectual passion) that "leads an author to overstate or denigrate research results, selectively withhold pertinent data or discussion, or exaggerate or minimize the shortcomings of the research." 4

Is it possible to have it all? Can sincere sophisticated professionals enjoy secondary interests while maintaining neutrality over their sway on our primary interests? Experimental social science research on the "self-serving bias" makes a compelling case that the answer, unfortunately, is frequently no. Individuals' judgments of what is fair are typically biased in favor of their self-interests. ${ }^{5}$ Dana and Lowenstein ${ }^{5}$ review a fascinating body of research illustrating the difficulty individuals have in taking a neutral objective perspective when they have a personal interest in arriving at a specific conclusion.

Closer to home, Bowman ${ }^{6}$ showed that, even when there are rules in place about fairness and nonuse of brand names, the courses underwritten by the drug company had more positive and fewer negative comments about the drugs of the funding company from the speakers at the podium. In a second study, Bowman and Pearle ${ }^{7}$ found that among groups of similar drugs ( $\beta$ blockers or calcium channel blockers), the drug of the funding company was reported to have more new prescriptions in the months following the course than the other similar drugs. The literature review of Wazana $^{8}$ found that attending drug companysponsored CME events and accepting funding for travel or lodging for educational symposia were associated with increased prescription rates of the sponsor's medication. Attending presentations given by pharmaceutical representative speakers was also associated with non-rational prescribing. Bowman and Pearle ${ }^{7}$ noted that attending such presentations also increased rational prescribing.

We agree with the following ethical framework to guide conflict identification, prevention and 
management, ${ }^{9}$ and we believe that health care providers and researchers will find this useful as a compass for maintaining their own professional integrity.

- Health care professions and organizations should provide care and conduct research to standards of scientific and moral excellence.

- Health care professions and organizations should use their knowledge and skills primarily to benefit patients. The pursuit of self-interest, no matter how legitimate, should become a secondary consideration.

- Health care professions and organizations are public trusts. They do not exist primarily for the benefit of physicians or organizational managers and owners. Instead, health care professions and organizations exist primarily to meet the health care needs of the communities of patients they serve and of future patients through research and education.

Is there evidence that conflict of interest (COI) has influenced science and biomedical publications? Several studies suggest that the answer is yes. ${ }^{10-13}$ Friedman and Richter ${ }^{14}$ studied COI and research results published in 2 leading general medicine journals. They used 3 different definitions of COI, and found that depending on the definition, the prevalence of COI by one or more authors varied between $19 \%$ and $29 \%$ of all original manuscripts published in both journals combined. They observed a strong association between positive study results and COI among all treatment studies, and also noted that the odds are extremely small that authors with COI would publish negative results.

As editors, our primary concern is in the communication of peer-reviewed information to improve the health of patients. Charlton ${ }^{15}$ defines peer review as the primary evaluation process of applied science and states that despite its convenience, peer review has significant limitations related to its reliance on opinion. One major limitation is its inability to deal with conflicts of interest, especially in a "big science" context when prestigious scientists may have similar biases, and conflicts of interest are widely shared among peer reviewers (cf 16). In the short term, Charlton ${ }^{15}$ suggests that reliance on peer review may allow damaging distortions to become "locked-in" to clinical practice and health policy.
Although it is beneficial to be reminded of the limitations of peer review, journals do not have the resources nor the mission to investigate conflict of interest. It is the responsibility of the entire community of authors, reviewers, and readers to identify and manage conflicting and competing interests. First, as discussed above, they are best avoided. Second, we ask authors to be forthcoming in considering and reporting their conflicts. Although a competing interest does not necessarily invalidate the work of the individual with the conflict, it is important to make this information available to peer reviewers. Third, we ask peer reviewers to consider how conflicts may have distorted the research questions, study designs, data reporting, and interpretation of findings. Finally, we ask readers to make their own judgments about the likelihood that conflicts may have introduced bias in the research report or practice guideline, and to participate in post-publication peer review by commenting on the published literature.

The $7 A B F P$ "Instructions for Authors" includes a number of policy statements that were developed for the purpose of increasing awareness of ethical standards in biomedical research and publishing. The statement on Competing Interests is as follows:

"The $7 A B F P$ supports and adheres to policy statements that are designed to increase disclosure and transparency related to competing interests and conflicts of interest. ${ }^{17,18}$ The 7 ABFP expects authors to disclose any commercial associations that pose, or have the appearance of posing, a conflict of interest in connection with the submitted article. Employment, consultancies, stock ownership or other equity interests, patent-licensing arrangements, and other kinds of associations that might involve conflict of interest should be disclosed at the time of submission."

Admittedly, this is a narrow definition of COI because it only addresses overt financial conflicts of interest. ${ }^{14}$ The fournal will now routinely ask authors to include real or potential COI declarations at the time of manuscript submission. Following the guidelines in the Uniform Requirements, ${ }^{17}$ all authors should disclose the details of their relationship with the funder, or any other associations that might have the appearance of a COI. For pharmaceutical industry-sponsored projects, authors are asked to describe the sponsor's role in the design, analysis, and reporting of the study data, as well as 
to document that they had access to the data, and they were able to make publication decisions independently. ${ }^{19}$ If there has been no such involvement, this should be stated as well. Rapid Review, our web-based manuscript submission software, has a new required field for such declarations in the author submission form.

Anne Victoria Neale, $\mathrm{PhD}, \mathrm{MPH}$

Kendra L. Schwartz, MD, MSPH

Marjorie A. Bowman, MD, MPA

\section{References}

1. Genuis SJ. The proliferation of clinical practice guidelines: professional development or medicineby-numbers? J Am Board Fam Pract 2005;18:41925.

2. Abramson J, Starfield B. The effect of conflict of interest on biomedical research and clinical practice guidelines: can we trust the evidence in evidencebased medicine? J Am Board Fam Pract 2005;18: 414-8.

3. Thompson D. Understanding financial conflicts of interest. N Engl J Med 1993;329:573-6.

4. [Editorial]. Publishing commentary by authors with potential conflicts of interest: When, why, and how. Ann Intern Med 2004;141:73-4.

5. Dana J, Loewenstein G. A social science perspective on gifts to physicians from industry. JAMA 2003;29: 252-5.

6. Bowman MA. The impact of drug company funding on the content of continuing medical education. Möbius 1986;6:66-9.

7. Bowman MA, Pearle DL. Changes in drug prescribing patterns related to commercial company funding of continuing medical education. J Cont Educ Health Prof 1988;8:13-20.

8. Wazana A. Physicians and the pharmaceutical industry. Is a gift ever just a gift? JAMA 2000;283:373-80.
9. Chervenak FA, McCullough LB. An ethical framework for identifying, preventing, and managing conflicts confronting leaders of academic health centers. Acad Med 2004;79:1056-61.

10. Perlis CS, Harwood M, Perlis RH. Extent and impact of industry sponsorship conflicts of interest in dermatology research. J Am Acad Dermatol 2005;52: $967-71$.

11. Kjaergard LL, Als-Nielsen B. Association between competing interests and authors' conclusions: Epidemiological study of randomized clinical trials published in the. BMJ 2002;325:249.

12. Schulman KA, Seils DM, Timbie JW, Sugarman J, Dame LA, Weinfurt KP, Mark DB, Califf RM. A national survey of provisions in clinical-trial agreements between medical schools and industry sponsors. N Engl J Med 2002;347:1335-41.

13. Choudhry NK, Stelfox HT, Detsky AS. Relationships between authors of clinical practice guidelines and the pharmaceutical industry. JAMA 2002;287: 612-7.

14. Friedman LS, Richter ED. Relationship between conflicts of interest and research results. J Gen Intern Med 2004;19:51-6.

15. Charlton BG. Conflicts of interest in medical science: peer usage, peer review and 'Col consultancy'. Med Hypotheses 2004;63:181-6.

16. Drazen JM, Curfman GD. Financial associations of authors. N Engl J Med 2002;346:1901-2.

17. International Committee of Medical Journal Editors. "Uniform Requirements for Manuscripts Submitted to Biomedical Journals." Available at: www.icmje.org. Accessed July 5, 2005.

18. DeAngelis CD, Fontanarosa PB, Flanagin A. Reporting financial conflicts of interest and relationships between investigators and research sponsors. JAMA 2001;286:89-91.

19. Davidoff F, DeAngelis C, Drazen JM, Hoey J, Hojharrd L, Horton R. Sponsorship, authorship, and accountability. Lancet 2001;358:854-6. 